\title{
The Interconnection of School Culture and Educational Management
}

\author{
Olga Kravets ${ }^{1}{ }^{*}$ Tatiana Klikushina ${ }^{1}$, Elena Palmova ${ }^{1}$, Natalya Shchitova ${ }^{1}$ \\ ${ }^{I}$ Taganrog Institute named after A.P. Chekov, Branch of Rostov State University of Economics, Russia \\ "Email: olgakravets@list.ru
}

\begin{abstract}
The paper examines the key issues of formation and promotion of the school culture under multiculturalism conditions in modern society. It discloses the important role of the school principal and administration in supporting appropriate school culture. School administration and pedagogical staff must meet the learning demands of students from culturally different backgrounds. The authors highlight how necessary it is to realize the importance of traditions and customs of the people surrounding you to achieve understanding, mutual collaboration, and progressive development of every personality and society. Thorough insight into the issue of multiculturalism in the system of education and its interconnection with effective school management is the key point of the paper.
\end{abstract}

Keywords: School culture, Cultural elements, Educational management, Professional challenge, Learning process, Multiculturalism in modern society.

\section{INTRODUCTION}

\subsection{Professional challenge}

This paper aims to identify, close examine, and critical exploration of one of the major professional challenges that the school administration has to face, namely - the formation and promotion of the school culture under the conditions of multiculturalism in modern society. Administration body and teaching staff should meet the demands of students from culturally various backgrounds. They should be professionally equipped to be aware of the challenges related to the need of cultural identity support and achieving educational targets. Educational institutions are also empowered with the opportunity to consolidate the ties within the community. They are responsible for the promotion of efficient intercultural communication among students. Some of the research questions being addressed include: What components should school culture consist of in order to create favourable background for students' achievements? How to raise the awareness of cultural differences and enhance collaboration? How can educational institutions and communities cooperate to promote cultural cohesion in diverse cultural environments and various settings?

\subsection{Professional context}

The topic of school culture and the role of principals' in its formation is especially interesting and urgent for me as the students studying and working in a multicultural environment fully realize the crucial role of the knowledge and ability to adopt the traditions and customs of the people surrounding them to achieve understanding, mutual collaboration and progressive development of every personality and society as a whole.

The efficiency of educational leadership has a great impact on the school culture in the context of the instruction, multiculturalism and the students' performance. The school's psychological climate, the instructional medium, and the insurance of respect and understanding of culturally diverse students' backgrounds are the conditions for successful teaching and learning. Therefore, the style of leadership which school principals choose can facilitate the achievement of educational goals or vice versa hamper the progress. This paper highlights that educational leaders are responsible for ensuring efficient school management as a system. It 
is held herein that efficient leadership is closely connected with the exercise of control over the teaching process. This paradigm has a great impact on the school's culture and students' academic performance.

\section{DISCUSSION}

\subsection{The Definition and Role of School's Culture. Culture and Climate}

In spite of being the main condition for the creation of the favourable school environment, the term "school culture" has not been clearly defined yet. This aspect is often taken for granted and even underestimated by some researchers. To begin with, culture plays a great role in all activities within the educational environment including the dress code, the way of communication among the teaching staff and students, the instructional style and the approach adopted to student learning. The research reveals that the climate at school can be changed without much effort in comparison with the change of cultural tradition. For instance, the events can trigger the changes. An organization's climate can be changed compared to the change in culture [1]. If the teachers have a higher level of psychological satisfaction does it mean that they will be better teachers, and what are the reasons for their psychological well-being? What are the conditions of positive climate? Probably all that school principals should do is an effort to create and maintain favourable conditions for staff and students. The strategy which will be based on moral values and aimed at mutual respect and effective cross-cultural communication will be a success. Types of educational management can be illustrated through their chief characteristics (table 1).

\subsection{Cultural Elements}

Research Studies of efficient school systems have defined several cultural components that are proved to impact student academic performance. Fyans and Maehr underlined the importance of a community sense, striving for achievement and vision of common goals as essential aspects [2]. Cheong highlighted managerial style, collaboration, leader's charisma, other researchers [3-5] underlined the importance of leadership based on moral values.

\subsection{School Climate and Learning Process}

In the course of study it has been proved that the relevance of school climate and its influence on learning process is considerable. In schools with favourable school climate collaborative environment is promoted and students feel able to excel and protected from the harmful influence of societal vices, such as drugs and criminals. The representatives of pedagogical community should pay as much attention as possible to psychological climate at school and appropriate culture in terms of traditional interests like curriculum design and methods of teaching. Educational institutions should become a platform for students' development in many senses. Students from broken families need special attention and support of the specialists, they need to be involved in various extracurricular activities and discover their strengths. Such issues as mutual help, understanding and respect of cultural differences, fostering learning ethics, cherishing moral values are the key cultural elements keeping in mind that each school is identical with its own culture, traditions, way of communication and even mindset.

\section{RESULTS. RESEARCH QUESTIONS}

Some further questions for discussion:

1. What is the relevance of international school model?

Table 1. Types of Educational Management and their Chief Characteristics

\begin{tabular}{|l|l|}
\hline \multicolumn{1}{|c|}{ Types of Educational Management } & \multicolumn{1}{c|}{ Chief Characteristics } \\
\hline Democratic & Sharing responsibility \\
& Equality \\
& Freedom \\
& Cooperation \\
\hline Autocratic & State Monopoly \\
& Centralized \\
& Dominated by bureaucracy \\
& Strict administration of laws, rules and regulations \\
\hline Centralized & Supervision and control \\
\hline Decentralized & Distribution of powers and responsibilities \\
\hline
\end{tabular}


2. In what ways national cultures have an effect on school culture?

3. As there are representatives of various nationalities with different cultural background within our teaching staff or student body, is it crucial for a principal to adapt his leadership?

Following the inherent traditions and customs is sometimes not congenial with cooperation spirit which is often mentioned but hard to achieve. How is it possible to foster a collaborative culture with respect to cultural diversity and national differences? How can school culture facilitate mutual understanding?

Leader's role in developing school culture is hard to overestimate. One of the main functions of strong leadership is to promote moral values and social norms. At the same time Robert Starratt mentions that simply the assumption that schools are an embodiment of desirable standards is considered naive by the author [7]. Thus, the educational leader must not only act responsibly as a person but should create an ethical system at school.

One of the main priorities of a successful modern leader is the ability to exercise authority ethically. Many researchers, Greenfield among them, suppose that principal's authority should be above all moral, thus ensuring that the views and actions of teaching staff reflect the moral values they proclaim [6]. The influence of formal bureaucratic administration will seldom have a lasting effect. As reseacher Thomas Sergiovanni claims, leader's actions are the expression of school culture [8]. Relationship is the foundation of culture. How people communicate, what they talk about, how often they contact with each other, what are the topics of their conversations. How much they respect each other, do they feel secure revealing their personal stories, are they confident in each other's positive attitudes? What are their values and beliefs? All these things determine the patterns of behaviour that become distinctive features of an organization. The moral purpose is a primary concern, relationships are crucial, - states Michael Fullan in "Leading in a Culture of Change" [4]. His chapter on the subject is entitled "Relationships, Relationships, Relationships," to underline their crucial role in school system [9]. Leaders do not have a choice whether they communicate, everything they do is a communication [10].

Understanding national cultures and educational values is the key to success. Effective collaboration is associated with shared values and good communication. It is well known that national cultures are characterised by different communication styles and different views on what good education is and what it is aimed at. As soon as these differences are determined they can be dealt with.

The outcomes of the survey carried out and analysed by the authors in 10 educational Institutes ( 6 secondary schools, 4 lyceums) of the Rostov region in September 2020 demonstrate which principles can be considered to be leading ones regarding educational management (table 2).

The research by Gruenert Steve revealed that studies on whether principals have an influence on the process of teaching show variations in terms of the conception and measurement of the leadership [1]. There is also a distinguished difference in the instruction practices. In the cases where leaders adopted an integrated approach to school leadership, there is evidence of synergetic effect which promotes teachers' creativity and ensures intellectual challenges. This contributes to systematic interconnectivity among teachers in resolving day-to-day tasks. This refers to educational policy objective which includes the creation of a favourable school environment, the understanding of shared values and respect to national cultures and other aspetcs (fig. 1).

The most far-reaching effect of the multicultural educational principles outlined by J.A. Banks concerns creating school cultures that are empowering to all students [11]. Empowering schools are designed and operated with thoughtful attention to the myriad ways that aspects of race and ethnicity can be encoded into a school's basic structures.

This discussion has embraced a wide array of empirical research and related literature. It is evident that that both district and school leadership provide a platform for implementation of educational reform initiatives [12].

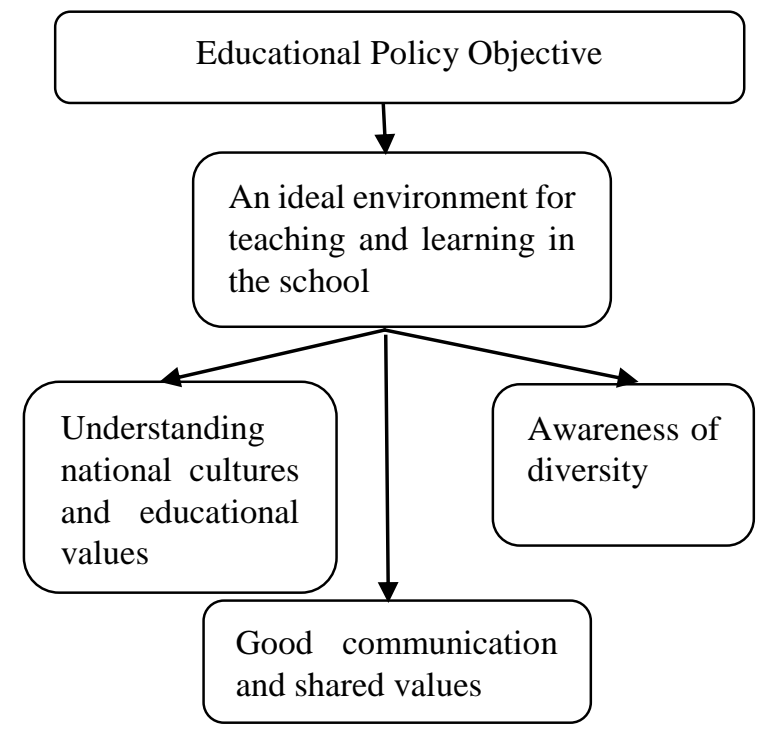

Figure 1 The Student-centered Educational Policy.

\section{CONCLUSION}

In conclusion, the school leaders, by applying their leadership styles, have an opportunity of creating an ideal environment for teaching and learning in the school. Concerning this, a school principal must demonstrate his 
leadership qualities instead of the objective of student performance or achievement. The following aspects are crucial for effective school culture: understanding of multiculturalism in all its aspects, shared educational values, collaborative culture, effective communication. The school culture created by committed school leadership and supportive teachers can ensure that the needs of the students will be met in terms of crosscultural awareness and the students will be able to discover and develop their interests, thus achieving academic success.

\section{REFERENCES}

[1] Gruenert Steve, School Culture and School Climate, 2008. Retrieved from: www.naesp.org.

[2] Fyans, L.J., Jr., and Martin L. Maehr, School Culture, Student Ethnicity, and Motivation, Urbana, Illinois: The National Center for School Leadership, ED 327 947, 1990.

[3] Cheong, Cheng Yin, Cultural Factors in Educational Effectiveness: a framework for comparative research, School leadership and Management Vol. 20 Iss. 2 (2000) 207-225.

[4] M. Fullan, Leading in a Culture of Change, New York, 2001.

[5] Deal and Peterson, Shaping School Culture, JosseyBass e-book, Introduction 'The research base and Impact', 2004, p.11.

[6] Greenfield, William D., Jr. Rationale and Methods To Articulate Ethics and Administrator Training. Paper presented at the annual meeting of the American Educational Research Association, Chicago, 1991, 32 P. ED 332379.

[7] Starratt, Robert J. Building an Ethical School: A Theory for Practice in Educational Leadership. Educational Administration Quarterly 272 (1991), 185-202.

[8] Thomas Sergiovanni, What is school culture? Retrieved from: http://abakhtiari.blogfa.com/1390/11

[9] Lewin \& Regine, School Culture and Organization. Retrieved from: https://www2.dpsk12.org/pdf/culture_organization. pdf

[10] Michael G. Thompson. Understanding School Culture (e-book), 2001.

[11] Banks, J.A., \& Banks, C.A.M. Handbook of research on multicultural education (2nd ed.), San Francisco, 2004.
[12] Kenneth Leithwood, Karen Seashore Louis, Stephen Anderson and Kyla Wahlstrom. How leadership influences student learning. University of Minnesota, 2004. 